\title{
Annealing effects on the adhesion of Tungsten-Titanium barrier layers
}

\author{
A. Kleinbichler ${ }^{1,2}$, J. Todt ${ }^{2}$, J. Zechner ${ }^{1}$, S. Wöhlert ${ }^{3}$, D. M. Többens ${ }^{4}$, M. J. Cordill ${ }^{2}$ \\ ${ }^{1} \mathrm{KAI}$ - Kompetenzzentrum Automobil- und Industrieelektronik GmbH, Technologiepark \\ Villach, Europastraße 8, Villach, Austria 9524 \\ ${ }^{2}$ Erich Schmid Institute for Material Science, Austrian Academy of Sciences and Dept. \\ Material Physics, Montanuniversität Leoben, Jahnstraße 12, Leoben, Austria, 8700 \\ ${ }^{3}$ Infineon Technologies AG, Siemensstraße 2, 9500 Villach, Austria \\ ${ }^{4}$ Helmholtz-Zentrum Berlin für Materialien und Energie, Albert-Einstein-Str. 15, 12489 \\ Berlin, Germany
}

\begin{abstract}
Tungsten-titanium (WTi) alloys are important barrier materials in microelectronic devices. Thus the adhesion of WTi to silicate glass substrates influences the reliability of these devices. One factor that affects the adhesion of barrier layers is thermal treatments during and after fabrication. To address the impact of annealing, WTi films deposited on silicate glass substrates were subjected to different annealing treatments. The stress development in the WTi film has been monitored with wafer curvature and X-ray diffraction. Quantitative measurements of the adhesion energies were performed using scratch testing to induce interface delamination. Imaging with atomic force microscopy provided the dimensions of the buckles to quantify adhesion energies. Focused ion beam cross-sections were used to verify the failing interfaces and to inspect any deformation in the film and the substrate caused by scratch testing. It was found that as the annealing duration increased, the residual compressive stresses in the film and the adhesion energy increased.
\end{abstract}




\section{Introduction}

Barrier layers are an important part of every integrated circuit. In metal-silicon oxide interfaces barrier layers provide the device with chemical as well as mechanical stability [1]. The chemical stability of the thin film system is meant as the prevention of diffusion of $\mathrm{Si}$ from the substrate into the conductive metal creating silicides, which significantly increases the electrical resistance. It is important that the chosen barrier material has a low reactivity with the conductive metallization and the underlying substrate, with thermal stability at high temperatures. A variety of studies have been conducted on this topic over the years following the advances of the microelectronics industry. Transition metals like $\mathrm{Cr}, \mathrm{Ti}, \mathrm{Mo}, \mathrm{Nb}$, $\mathrm{Ta}$ and $\mathrm{W}$, are very suitable materials for conductive diffusion barrier layers and several of these films have been investigated in the relevant temperature ranges that these films experience during production and service [2]. It was found that all of these materials were chemically stable up to $400^{\circ} \mathrm{C}$ for 1 hour.

A frequently used diffusion barrier for copper and aluminum metallizations is tungsten titanium (WTi) which exhibits good temperature stability and adhesion [3,4]. WTi is a solid solution of $\mathrm{W}$ and $\mathrm{Ti}$ with $\mathrm{W}$ usually being the major component and varying minor amounts of Ti. Several studies on the thermal stability of WTi have been conducted to determine the failure temperature of the film, where copper-silicide $\left(\mathrm{Cu}_{3} \mathrm{Si}\right)$ start to form. Barrier failure was discovered at temperatures between $700-800^{\circ} \mathrm{C}$ for different annealing times. Fugger et al [5] investigated the stability of the WTi barrier layer depending on the annealing times with respect to the copper layer on top. It was reported that the WTi barrier layer remained stable up to $600^{\circ} \mathrm{C}$ for four hours with no copper-silicide $\left(\mathrm{Cu}_{3} \mathrm{Si}\right)$ formation, although a segregation of $\mathrm{Ti}$ into the copper film was observed. The failure temperature was found at $650^{\circ} \mathrm{C}$ after 4 hours of annealing with the formation of $\mathrm{Cu}_{3} \mathrm{Si}$. No Ti segregation towards the copper film was found when annealing at $400^{\circ} \mathrm{C}$ for 8 hours. Völker et al [6] found that the segregation of $\mathrm{Ti}$ formed a few atom layers of $\mathrm{Ti}$ between the doped silicate glass substrate and the WTi layer which promoted the adhesion of the respective layer when annealing the sample to $400^{\circ} \mathrm{C}$ for 1 hour. This suggests that the adhesion of the WTi film to the substrate could be influenced by the annealing temperature and time.

Mechanical stability is mainly governed by the adhesion of the barrier layer to the conductive metallization and the substrate [1]. Several adhesion testing methods have been 
successful in quantitatively measuring the adhesion of thin films $[7,8]$. Common techniques include four point bending (4PB) [6,9-12], microcantilever tests [13,14], nanoindentation [15-18] and scratch tests [19-22]. Four point bending and microcantilever tests require very elaborate sample preparation and testing procedures which may also change the properties of the interface in question. Nanoindentation and scratch testing, on the other hand, allow the samples to be tested in the desired as-produced condition.

The adhesion of WTi to commonly used substrates like silicon or silicon oxides and its dependence on several parameters such as composition or film thickness, have also been investigated using several different methods $[6,9,23,24]$. In order to quantitatively measure the adhesion of the WTi film the scratch test has been utilized. This mechanical testing technique which induces compressive stress into the film causing delamination in different forms [19-21,25]. Scratch testing has been successful in inducing buckles in compressively stressed film in a thickness range of a few hundred nanometers [22,26].

The buckles produced with the scratch test can be evaluated by the model proposed by Hutchinson and Suo [27]. In the case of a hard metal film, like WTi, and a rigid glass substrate, very little plasticity is involved in the buckling process which allows for an elastic approximation. The stresses induced in the film and the associated adhesion energy can be calculated from the buckle height, $\delta$, and the half buckle width, $b$, the film thickness, $h$, and the elastic properties of the film (elastic modulus, E, and Poisson's ratio, $\nu$ ). The critical buckling stress, $\sigma_{b}$ of the interface and the driving stress, $\sigma_{d}$ in the film are calculated using equations (1) and (2),

$$
\begin{aligned}
\sigma_{b} & =\frac{\pi^{2} E}{12\left(1-v^{2}\right)}(h / b)^{2} \\
\sigma_{d} & =\sigma_{b}\left[\frac{3}{4}(\delta / h)^{2}+1\right] .
\end{aligned}
$$

The mixed mode adhesion energy, $\Gamma(\Psi)$, which represents the practical work of adhesion, is given by equation (3)

$$
\Gamma(\Psi)=\left[\frac{\left(1-v^{2}\right) h}{2 E}\right]\left(\sigma_{d}-\sigma_{b}\right)\left(\sigma_{d}+3 \sigma_{b}\right)
$$

In this study the adhesion of the WTi barrier layer to a silicate glass substrate is measured as a function of the annealing time. The annealing temperature was set at $400^{\circ} \mathrm{C}$ because the 
barrier layer experiences this annealing temperature for different time periods during production. The information about how the adhesion is influenced by the annealing time will allow for the optimization of the annealing time in order to achieve the best interfacial strength for the WTi-Borophosphosilicate glass interface.

\section{Experiment}

The studied samples were provided by Infineon Technologies Austria AG. They consisted of $725 \mu \mathrm{m}$ thick silicon wafers with a diameter of $200 \mathrm{~mm}$, coated with a dielectric layer and a metal barrier film. In the first deposition step, $800 \mathrm{~nm}$ of Borophosphosilicate glass (BPSG) was deposited on the wafers using plasma enhanced chemical vapor deposition followed by annealing at $900^{\circ} \mathrm{C}$. The $300 \mathrm{~nm}$ thick Tungsten-Titanium (WTi) barrier layer film was sputter deposited onto the BPSG where the $\mathrm{W}$ film contained 20 at $\%$ of $\mathrm{Ti}$, which is a common composition of this barrier layer for modern microelectronic devices. The WTi films were deposited under conditions that induced a compressive residual stress of about 1.5 GPa measured by wafer bow.

Equally sized pieces $(1 \times 1.5 \mathrm{~cm})$ of the wafers were annealed to $400^{\circ} \mathrm{C}$ using a heating rate of $10^{\circ} \mathrm{C} / \mathrm{min}$ and the temperature was held for $30 \mathrm{~min}, 45 \mathrm{~min}, 1$ and 2 hours. The annealing treatment was conducted in a vacuum chamber using a k-Space Associates MultiBeam Optical Sensor (MOS) wafer curvature system in order to monitor the stress evolution in-situ during annealing. The chamber operated at a pressure of about $10^{-4}$ mbar. Additionally, the stress in the WTi film has been measured for one sample heated in-situ to $400^{\circ} \mathrm{C}$ with a hold time of 1 hour with synchrotron X-ray diffraction (XRD). This experiment was carried out on the KMC-2 [28] beamline at BESSY II, Helmholtz-Zentrum Berlin für Materialien und Energie (HZB) using monochromatic radiation with a wavelength of $1.5504 \AA$ (equivalent to $\mathrm{Cu}-\mathrm{K} \alpha_{1}, 8048 \mathrm{eV}$ ), a spot size of $0.3 \mathrm{~mm}$ diameter and a Bruker VÅNTEC 2000 area detector operated with an exposure time of 7 seconds. The film stresses were determined utilizing the $\sin ^{2} \psi$ method [29] by measuring the shift in the WTi (110) peak which has been observed before [5,30,31]. The in-situ heating was conducted with an Anton Paar DHS 1100 heating device with a graphite dome under a residual air pressure of 10 mbar. The sample was heated with an effective rate of $12.5^{\circ} \mathrm{C} / \mathrm{min}$ from room temperature 
up to $400^{\circ} \mathrm{C}$. The temperature was increased in steps of $25^{\circ} \mathrm{C}$, with a hold time of 2 minutes to record the peak position. During the subsequent hold time of 1 hour at $400^{\circ} \mathrm{C}$ the peak position were recorded in 10 minute intervals. Afterwards, the sample was cooled down to $50^{\circ} \mathrm{C}$ in the same manner as the heating, again monitoring the peak position at each $25^{\circ} \mathrm{C}$ step. However, the times to reach these temperatures steps increased below $100^{\circ} \mathrm{C}$ due to the residual heat in the device, resulting in omitting the last temperature step from $50^{\circ} \mathrm{C}$ to $25^{\circ} \mathrm{C}$.

In order to measure the film stress, it was necessary to experimentally determine the $\mathrm{X}$ ray elastic constant $1 / 2 s 2$ of the WTi solid solution, which connects the lattice strain to the stress in the film. For this purpose, a procedure proposed by Eiper et al [32] was used and a new wafer was produced without the BPSG layer between the WTi and the Si substrate. This method determines the lattice strain $d_{\psi}{ }^{h k l}$ for different orientations of the film via the peak shift relative to the unstressed peak position. The macroscopic stress $\sigma_{11}$ in the film is calculated from the curvature $R$ of the silicon substrate, which is determined using the silicon (400) peak that lies perpendicular to the sample surface, and the Stoney formula [33],

$$
\sigma_{11}=\frac{E_{S}}{6\left(1-v_{S}\right)} \frac{h_{s}^{2}}{h_{f}} \frac{1}{R}
$$

where $h_{s}$ is the thickness of the substrate, $h_{f}$ is the thickness of the film, $E_{S}$ is the elastic modulus and $v_{s}$ is the Poisson's ratio of the Si substrate. Following this, the $\sin ^{2} \psi$ equation [29],

$$
\frac{\partial d_{\psi}{ }^{h k l}}{\partial \sin ^{2} \psi}=\frac{1}{2} s_{2}{ }^{h k l} d_{0}{ }^{h k l} \sigma_{11},
$$

with $d \sigma^{h k l}$ being the unstressed lattice spacing for the peak lattice plane family $h k l$ and $\psi$ the angle between the sample's surface normal and the crystal planes, is solved for the X-ray elastic constant $1 / 2 s_{2}{ }^{h k l}$. It should be noted, that this constant depends on the peak hkl used for stress analysis due to the possibility of crystallographic elastic anisotropy. Additionally the film stresses were measured using the $\sin ^{2} \psi$ method in a laboratory XRD after each annealing treatment in the wafer curvature vacuum chamber. The laboratory instrument was a Rigaku SmartLab 5-Axis X-ray diffractometer equipped with $\mathrm{Cu}-\mathrm{K} \alpha$ radiation, parabolic multilayer mirror incident optics, a graphite diffracted beam monochromator and a scintillation counter.

The scratch test experiments were performed on a Keysight G200 nanoindenter using a Berkovich tip. Both the sharp edge and the broad face of the pyramidal tip were utilized as 
the scratch front in order to induce different stress fields during scratching [19-21]. The length of all scratches was $500 \mu \mathrm{m}$ and the distance between the scratches was set to $500 \mu \mathrm{m}$ to avoid interaction with other scratches or the induced delaminations. The maximum load range was between $100-500 \mathrm{mN}$ with a scratch velocity of $30 \mu \mathrm{m} / \mathrm{s}$ and at least five scratches were made for each maximum load and tip orientation. A Zeiss LEO 1540 XP focused ion beam (FIB) microscope was used to examine the failed interfaces and any deformation due to the mechanical loading. To measure the buckle dimensions a Veeco Dimension DI3000 atomic force microscope (AFM) was used. The buckle measurements were taken from the AFM height images using Gwyddion software [34] and the film stresses and adhesion energy were calculated using the Hutchinson and Suo model [27] using Eqs. (1-3). The elastic modulus of the as-deposited and the annealed WTi films was determined from nanoindentation experiments using the continuous stiffness method and a well-calibrated, sharp Berkovich tip (not the same tip used for the scratching experiments). The modulus was measured to be $E_{W T i}=171.8 \mathrm{GPa}$ for the as-deposited film, at an indentation depth of about $30 \mathrm{~nm}$ which corresponds to $10 \%$ of the total film thickness. For the annealed WTi films no change in the elastic modulus was observed within the margin of error (Table I). The Poisson's ratio of WTi was determined using the rule of mixtures with $\nu_{W}=0.28$ and $\nu_{T i}=$ 0.32 , which yields $\nu_{W T}=0.288$.

In order to investigate possible changes of the interface chemistry the WTi film was removed from the BPSG substrate using Polyurethane Protective Tape with an acryl based adhesive. The substrate was then analyzed with Auger electron spectroscopy (AES) using a PHI 4700 Thin Film Analyzer with a scanned area of $20 \times 20 \mu \mathrm{m}$.

Table I: Measured elastic moduli (in GPa) of the WTi films after different annealing treatments.

\begin{tabular}{lllll}
\hline As-deposited & $400^{\circ} \mathrm{C} / 30 \mathrm{~min}$ & $400^{\circ} \mathrm{C} / 45 \mathrm{~min}$ & $400^{\circ} \mathrm{C} / 1 \mathrm{hr}$ & $400^{\circ} \mathrm{C} / 2 \mathrm{hr}$ \\
\hline $171.8 \pm 11$ & $173.2 \pm 27$ & $179.8 \pm 26$ & $169.5 \pm 16$ & $180.1 \pm 14$ \\
\hline
\end{tabular}




\section{Results and Discussion}

Wafer curvature and in-situ XRD measurements revealed an increasing change in residual stress in the samples towards more compression with increasing annealing times. Results from wafer curvature measurements are presented in Figure 1a. The longer the hold time at $400^{\circ} \mathrm{C}$ the more compressively stressed the films became. After 30 minutes of annealing the WTi film stress increased by about $4 \%$, after one hour by $11 \%$ and by $22 \%$ after two hours compared to the original film stress. The increased stress remained after cooling to room temperature. The same behavior was also observed in the in-situ XRD heating measurement for a hold time of 1 hour shown in Figure 1b. The absolute values of the film stress differed from those measured with wafer curvature since the curvature of the whole sample system including the BPSG and Si was measured, resulting in lower overall stress values [35]. For the in-situ XRD heating experiments the film behavior was qualitatively similar to the wafer curvature measurements. The compressive stress in the WTi film also increased during the hold time and remained about $10 \%$ higher compared to before annealing, illustrating that the stress develops mainly in the WTi film. The magnitude of the

a)

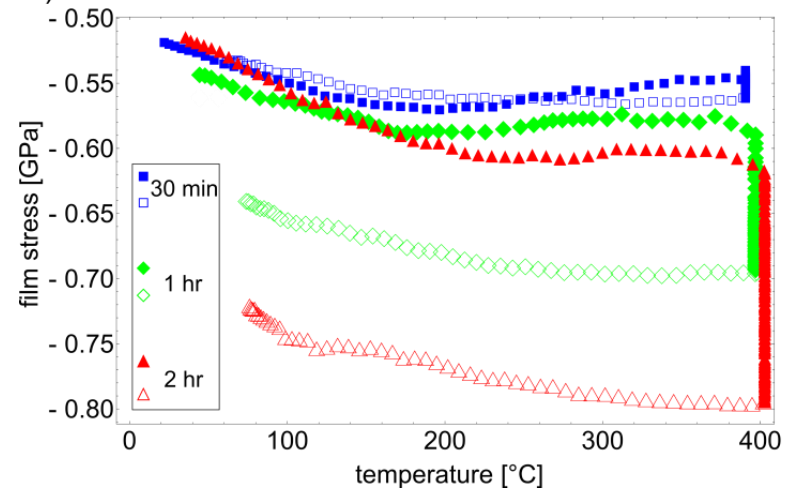

b)

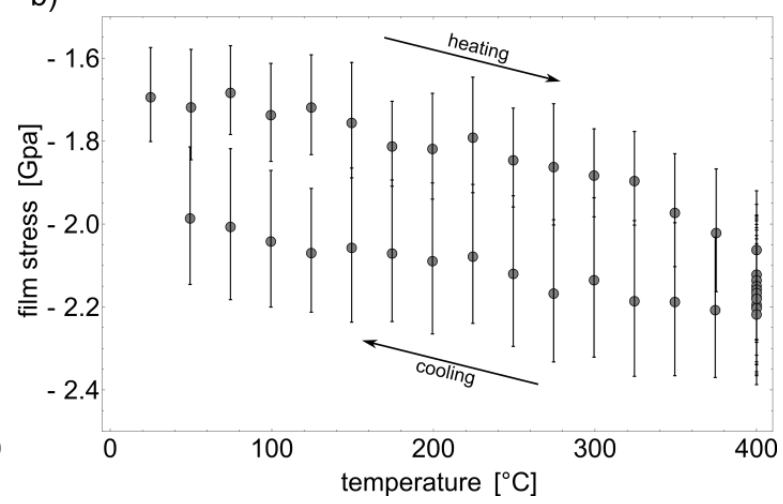

Figure 1: The development of stress in the film stack and the WTi film, measured by (a) wafer curvature for the samples annealed for $30 \mathrm{~min}, 1$ hour and 2 hours and (b) by in-situ XRD for a sample annealed for 1 hour. The solid symbols in (a) represent the heating and the open symbols represent the cooling cycle. The temperature axis of the $30 \mathrm{~min}$ and the 2 hour annealed sample was shifted by $-5^{\circ} \mathrm{C}$ and $+5^{\circ} \mathrm{C}$, respectively, to avoid the overlap of the curves. Both measurement methods reveal that the compressive stress in the film increased as a function of the hold time at $400^{\circ} \mathrm{C}$. 
error bars in Figure 1b are a result of thermal fluctuations during the measurement and the slight texture in the WTi film. The increase of compressive stress during the hold time most likely helps to induce delaminations during scratching. It is possible that the increase in stress originated from the segregation of the Ti to the interface, which in turn also may lead to an increase of adhesion [6].

The scratches performed on the as-deposited sample with maximum loads of $300-500$ $\mathrm{mN}$ exhibited buckles using both indenter tip orientations (sharp and broad). For maximum loads of $300 \mathrm{mN}$ each scratch produced an average of 3 buckles, at $400 \mathrm{mN} 5$ buckles per scratch were observed and at $500 \mathrm{mN}$ more than 10 buckles were produced utilizing the sharp side of the tip. An example is shown in Figure 2a. When using the broad side of the tip similar amounts of buckles were produced at the same loads, however, some of the buckles were spalled off the surface and through thickness cracking of the film occurred at loads of 400 $\mathrm{mN}$ and higher [19-21].

For the sample annealed at $400^{\circ} \mathrm{C}$ for 30 minutes the only scratches performed using the broad side of the tip were able cause interface separation. At maximum loads of 400 and 500 $\mathrm{mN}$, scratches produced an average of about 2 to 3 buckles growing outward from the trace (Figure 2b). Similar to the sample with 30 min of annealing time, the scratches on the sample annealed for 45 min resulted in buckles with both tip orientations, at maximum loads of 400 and $500 \mathrm{mN}$. At loads of $400 \mathrm{mN}$ fewer buckles were produced than at $500 \mathrm{mN}$, where 2 to 3 buckles formed per scratch. After annealing the sample for 1 hour, the scratches made with the sharp and broad side of the tip produced buckles at maximum loads of 400 and $500 \mathrm{mN}$ (Figure 2c). The buckles appeared to develop at random sites along the trace with no clear connection to maximum load or scratch distance. The annealing treatment of 2 hours resulted in a similar number and distribution of buckles as the 1 hour annealing.

The role of the tip orientation changed with each annealing duration, however, on average the broad side of the tip seemed to be more efficient at inducing buckling, even though this orientation can be accompanied by more spallation. Blunting of the tip is also a factor, since the tip was exposed to a significant amount of wear during scratch testing and can also influence the buckle development [19-21]. 

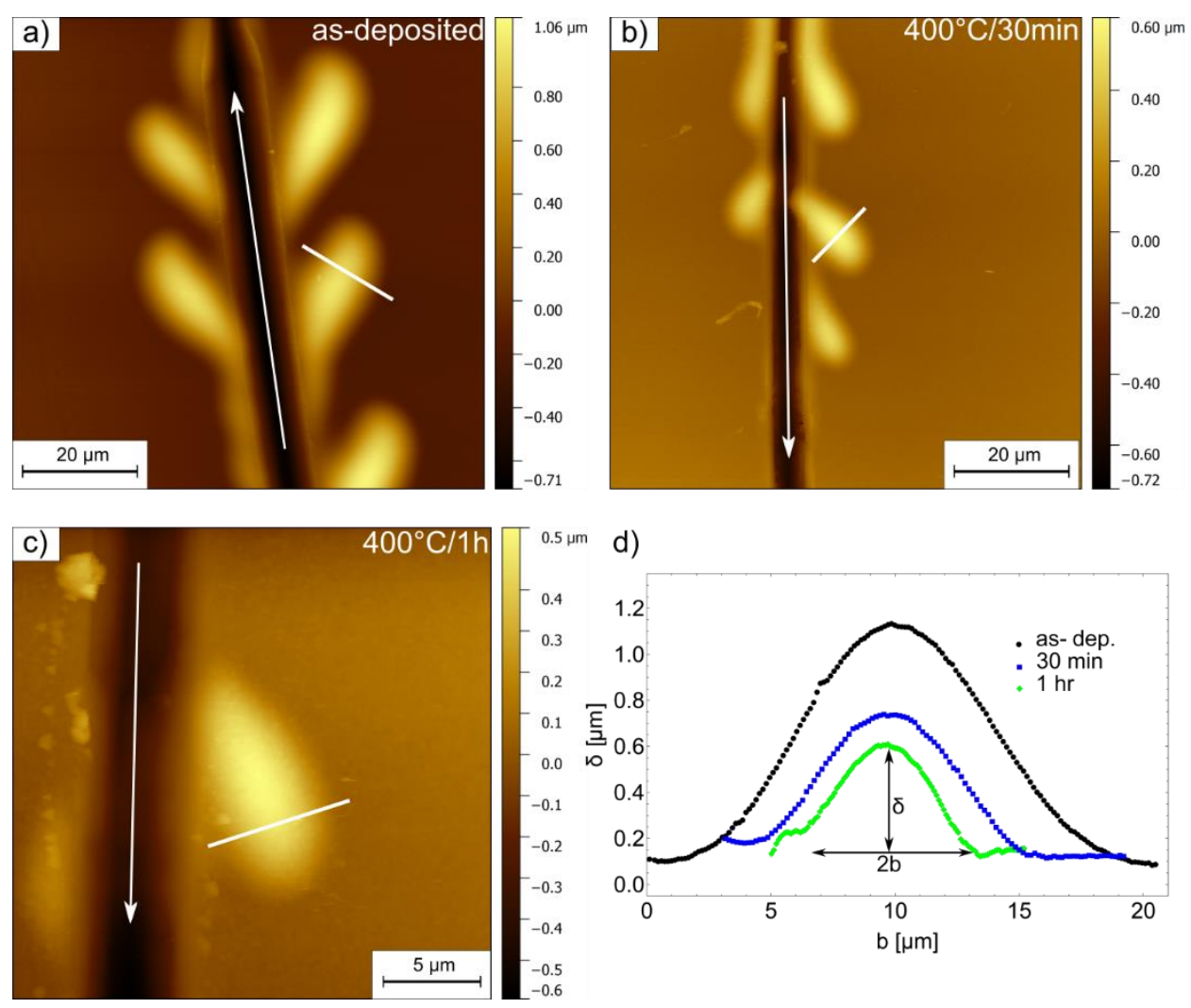

Figure 2: AFM height images of the scratch-induced buckles produced on the (a) as-deposited and films annealed at $400^{\circ} \mathrm{C}$ for (b) $30 \mathrm{~min}$ and (c) one hour with the arrows indicating the scratch direction. All buckles shown here were produced from scratches with a maximum load of $400 \mathrm{mN}$ (scratch direction indicated by white arrows). The height profiles of these buckles indicated by the white lines in (a-c) are shown in (d) with the required measurements for the adhesion calculation depicted. A clear decrease in buckle height and width can be observed with increasing annealing time.

Generally, the amount of buckles significantly decreased as a result of the increasing annealing times and qualitatively suggests an increase in the adhesion energy. In order to quantitatively evaluate the adhesion of the film to the substrate the buckles were imaged with the AFM and the heights and widths measured. Each buckle was measured in three different places to ensure good statistics. When comparing the buckle dimensions for the different annealing treatments it can clearly be seen that the buckle sizes decreased with increased annealing times shown in Figure 2d, where the AFM profiles illustrate the decrease in buckle width and height. This behavior is another qualitative indicator of increase of the adhesion energy due to the annealing treatments. 
Even though the film stresses increased due to the annealing, the buckle dimensions decreased. However, according to Eq. 1 and 2 the buckles should become larger if the adhesion energy is constant. The stresses of the WTi film measured with XRD and calculated from the buckle dimensions using Eqn. 2 are shown in Figure 3 and illustrate that the compressive stresses increased with longer annealing times. The values of film stress compare well up to 45 min of annealing time. For longer hold times the calculated values start to deviate from the measured values, when the buckles become much smaller. The deviation is most likely due to the fact that the calculation is very sensitive to the measured buckle dimension and slight errors can change the result. The fact that the buckles actually become smaller despite the increasing film stress can be attributed to an increased adhesion energy. However, as shown in Figure 3, the errors of the measured and the calculated film stresses for 1 and 2 hours of annealing overlap at the higher end and showed the same trend.

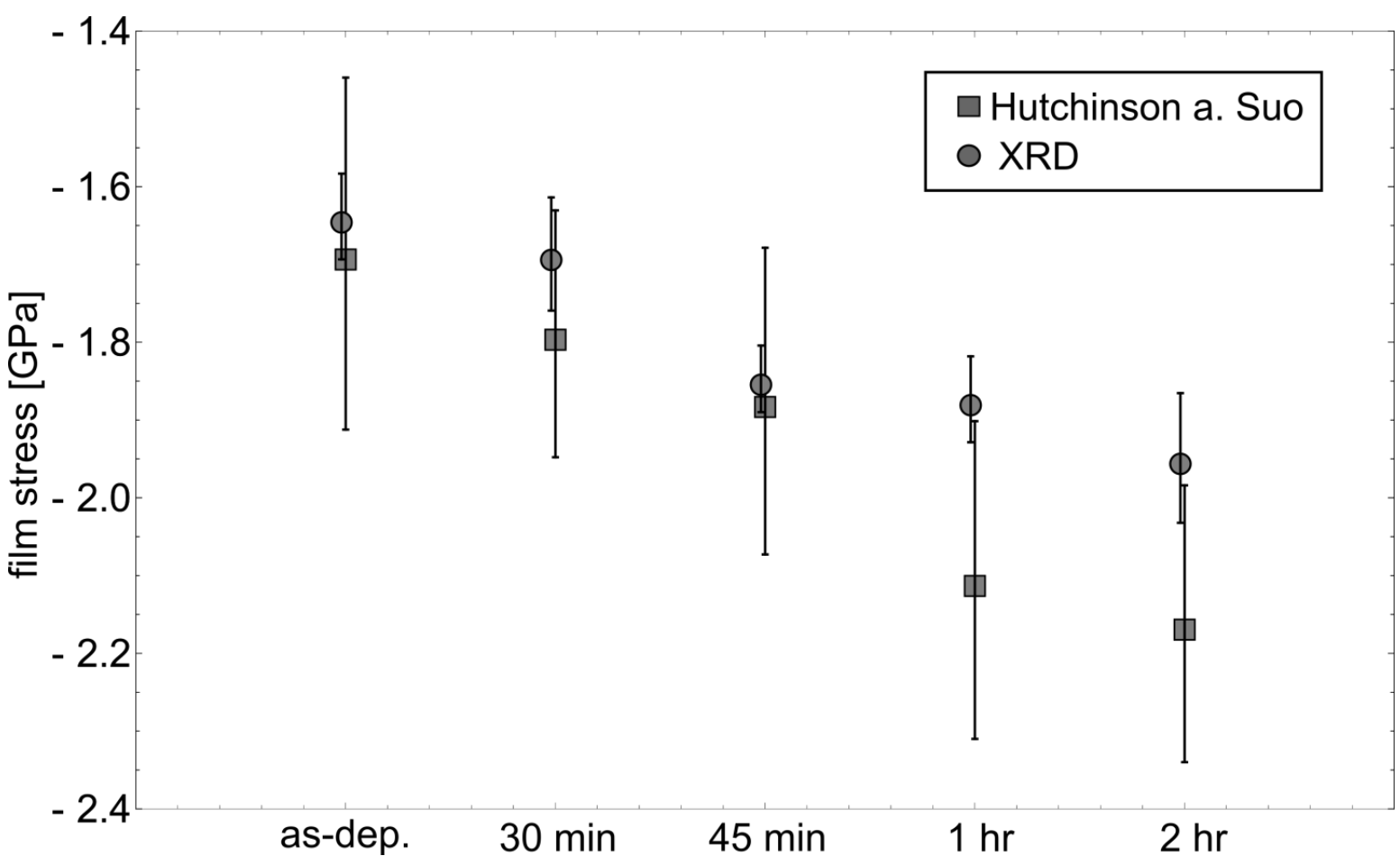

Figure 3: Film stress of the as-deposited and the annealed samples measured by XRD and calculated from Eqn 2. An increase of compressive stress due to annealing time can be seen for the measured and the calculated film stress values.

The FIB cross-section in Figure 4 demonstrate the interface separation for a buckle growing outward from the scratch trace. It is important to measure the profile of the buckles at a place far enough away from the trace, as illustrated in Figure 2 (white lines). This is the 
equilibrium region of the buckle where the height and width are constant with respect to the delamination growth direction and are more representative of the interface behavior. If the buckle is measured too close to the scratch trace the interfacial crack path might still be connected to the trace due to plastic deformation of the film and substrate. The measurements of the height and width of the buckles were taken sufficiently far away from the trace in order to avoid the areas where the buckle size could have been affected by plastic deformation from the scratch trace.

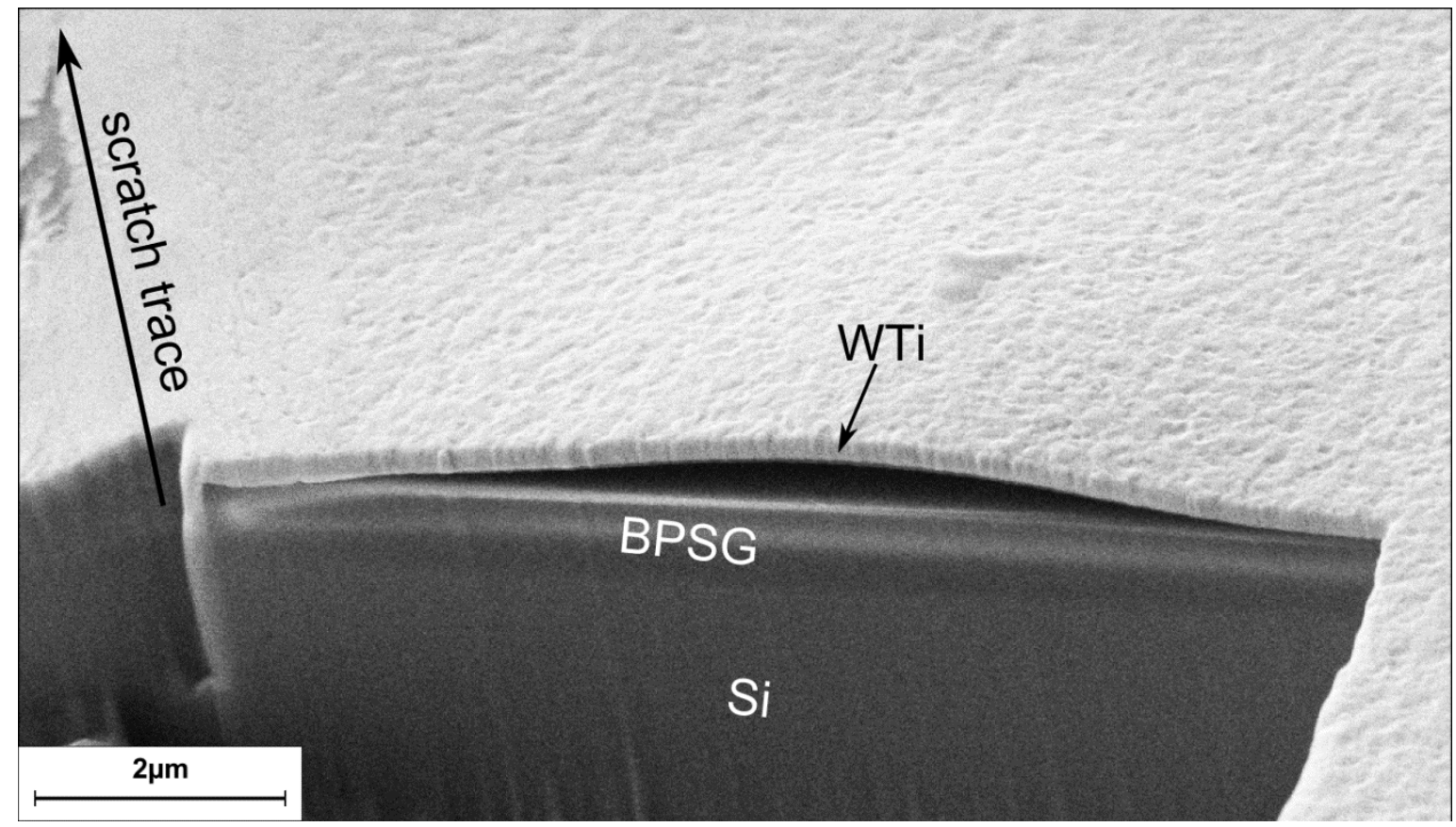

Figure 4: FIB cross-section of a buckle initiated from a scratch trace, made with a maximum load of $400 \mathrm{mN}$ on a sample annealed for 30 minutes. A clear interface separation between the BPSG and the WTi film can be seen.

The film stress and mixed mode adhesion energy $\Gamma(\Psi)$ were calculated from the measured buckle dimensions, the film thickness and elastic properties (Table I) using the model by Hutchinson and Suo (Eqs. 1-3) [27]. The buckles were modeled as spontaneous straight sided buckles. The results for the adhesion energies are shown in Figure 5. A significant increase in the adhesion energy after annealing was determined from the respective buckles. The adhesion energy of the as-deposited film was $2.7 \mathrm{~J} / \mathrm{m}^{2}$ and increased continuously to $4.7 \mathrm{~J} / \mathrm{m}^{2}$ after two hours of annealing at $400^{\circ} \mathrm{C}$. The adhesion energy for the as-deposited WTi film is similar to that of pure tungsten on glasslike substrates, which is 
know from literature to be in the range of $2.5-3 \mathrm{~J} / \mathrm{m}^{2}[9,13,15,22]$. This indicates that the Ti content in the alloy does not significantly contribute to the adhesion of the system in the asdeposited state. The annealing treatment increased the adhesion of the system most likely due to the segregation of Ti from the WTi solid solution towards the interface, creating a titanium film that is only a few atom layers thick and promotes adhesion [6,9]. This process takes more than 30 minutes since a significant increase in adhesion was not detected within the margin of error. However, the adhesion of the WTi film increased continuously with increasing annealing time up to 2 hours. Longer annealing times have not yet been investigated, however, from Figure 5 it appears as though the adhesion energy reached a plateau around $4.7 \mathrm{~J} / \mathrm{m}^{2}$ since the difference between the 1 and 2 hour annealing times is only $\sim 0.2 \mathrm{~J} / \mathrm{m}^{2}$, which is basically the resolution of the measurement. It should be noted that, longer annealing times would also increase the production time and costs of devices and can also have a negative impact on barrier stability.

The mixed mode adhesion energy calculated for the 1 and 2 hour annealing times compare well to the values measured from other methods for similar samples. For instance, 4PB performed by Völker et al [6,9] calculated an adhesion energy of 4.9-6 J/m² and microcantilever experiments by Matoy et al [13] which resulted in adhesion energies of 4.3 $\mathrm{J} / \mathrm{m}^{2}$. Fugger et al [5] detected a further increase of Ti segregation towards the copper above the WTi layer up to 16 hours of annealing at $600^{\circ} \mathrm{C}$. Völker et al [9] investigated the effect of different contents of $\mathrm{Ti}(15 \mathrm{at} \%-25 \mathrm{at} \%)$ in the WTi alloy on adhesion and found no significant change in adhesion energy between the different films chemistries. This would further suggest that a saturation of Ti segregation at the BPSG interface is reached after less than two hours of annealing at $400^{\circ} \mathrm{C}$ when the adhesion of the WTi film is equal to pure Ti of about $6 \mathrm{~J} / \mathrm{m}^{2}[9]$.

The AES analysis of the BPSG surface revealed that Ti was present on all samples and W was not detected on the BPSG surface after the removal of the WTi film with the tape. A quantification of the $\mathrm{Ti}$ amount was not possible due to the overlap of $\mathrm{Ti}$, $\mathrm{TiOx}$ and $\mathrm{TiSi}_{2}$ Auger peaks. 


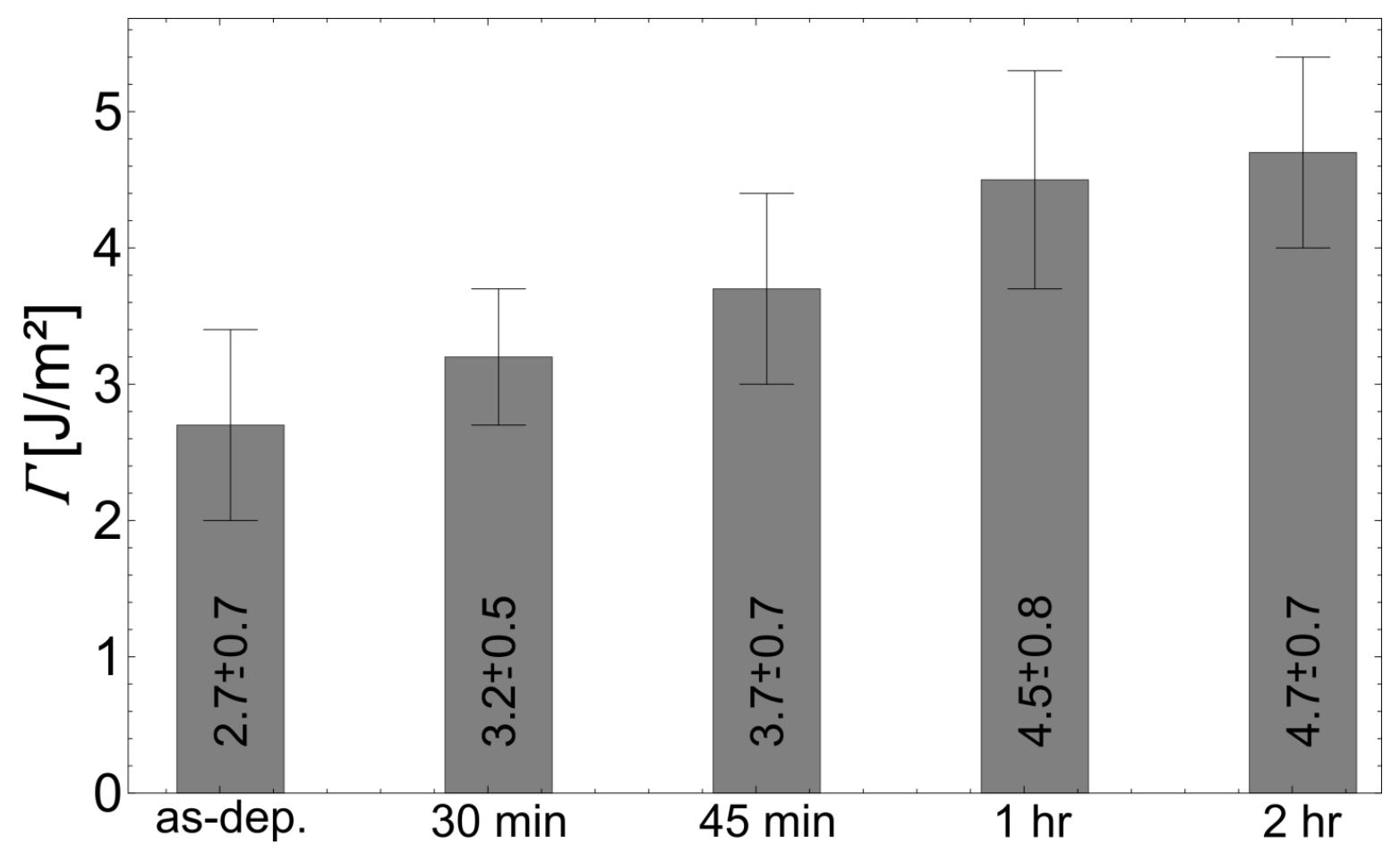

Figure 5: The mixed mode adhesion energies, $\Gamma(\Psi)$, for the as-deposited and the annealed WTi films. The adhesion energy increases continuously with the annealing time up to approximately 1-2 hours.

\section{Conclusion}

The current study illustrated how the duration of annealing treatments affect the film stress and the adhesion of a WTi barrier layer alloy to BPSG. The stress in the WTi film became increasingly more compressive the longer it was annealed at $400^{\circ} \mathrm{C}$, demonstrated by in-situ wafer curvature and synchrotron XRD experiments. Through the use of scratch induced delaminations the adhesion energies of the WTi barrier layer and BPSG substrate could be quantitatively measured. The buckle size and amount decreased significantly as the annealing times were increased and the calculated film stresses were in good agreement with the stresses measured with laboratory XRD. From the buckle dimensions the adhesion energy of the WTi film to the BPSG substrate was calculated and showed the increase of interface strength with annealing time, revealing a plateau between 1 and 2 hours annealing time. The increase of film stress and adhesion is believed to be due to the segregation of Ti from the film, which changes the interface chemistry. 


\section{Acknowledgements}

The authors want to thank C. Trost, B. Putz and A. Leitner of the Erich Schmid Institute and T. Pelisset, V. Haberl and S. Zoth of Infineon Technologies Austria AG for experimental assistance. The authors would like to acknowledge HZB for the allocation of synchrotron radiation beamtime and thankfully acknowledges the financial support by HZB (project 16224035-ST). This work was jointly funded by the Austrian Research Promotion Agency (FFG: Project No. 846579) and the Carinthian Economic Promotion Fund (KWF, contract KWF-1521/26876/38867) further financial support by the Austrian Federal Government (837900) within the framework of the COMET Funding Program is appreciated.

\section{References}

[1] S.P. Murarka, Multilevel interconnections for ULSI and GSI era, Mater. Sci. Eng. R Reports. 19 (1997) 87-151. doi:10.1016/S0927-796X(97)00002-8.

[2] H. Ono, T. Nakano, T. Ohta, Diffusion barrier effects of transition metals for $\mathrm{Cu} / \mathrm{M} / \mathrm{Si}$ multilayers (M=Cr, Ti, Nb, Mo, Ta, W), Appl. Phys. Lett. 64 (1994) 1511-1513. doi:10.1063/1.111875.

[3] S.Q. Wang, S. Suthar, C. Hoeflich, B.J. Burrow, Diffusion barrier properties of TiW between Si and Cu, J. Appl. Phys. 73 (1993) 2301-2320. doi:10.1063/1.353135.

[4] J.-C. Chiou, K.-C. Juang, M.-C. Chen, TiW(N) as diffusion barriers between $\mathrm{Cu}$ and Si, J. Electrochem. Soc. 142 (1995) 2326-2331. doi:http://dx.doi.org/10.1149/1.2044295.

[5] M. Fugger, M. Plappert, C. Schäffer, O. Humbel, H. Hutter, H. Danninger, et al., Comparison of WTi and WTi(N) as diffusion barriers for $\mathrm{Al}$ and $\mathrm{Cu}$ metallization on Si with respect to thermal stability and diffusion behavior of Ti, Microelectron. Reliab. 54 (2014) 2487-2493. doi:10.1016/j.microrel.2014.04.016.

[6] B. Völker, W. Heinz, K. Matoy, R. Roth, J.M. Batke, T. Schöberl, et al., Interface fracture and chemistry of a tungsten-based metallization on borophosphosilicate glass, Philos. Mag. 6435 (2014) 1-15. doi:10.1080/14786435.2014.913108.

[7] A.A. Volinsky, N.R. Moody, W.W. Gerberich, Interfacial Toughness Measurements for Thin Films on Substrates, Acta Mater. 50 (2002) 441-466. doi:10.1016/S1359-6454(01)00354-8.

[8] K.L. Mittal, The role of the interface in adhesion phenomena, Polym. Eng. Sci. 17 (1977) 467-473. doi:10.1002/pen.760170709.

[9] B. Völker, W. Heinz, K. Matoy, R. Roth, J.M. Batke, T. Schöberl, et al., Mechanical and chemical investigation of the interface between tungsten-based metallizations and annealed borophosphosilicate glass, Thin Solid Films. 583 (2015) 170-176. doi:10.1016/j.tsf.2015.03.047.

[10] R.H. Dauskardt, M. Lane, Q. Ma, N. Krishna, Adhesion and debonding of multi-layer thin film structures, Eng. Fract. Mech. 61 (1998) 141-162. doi:10.1016/S0013-7944(98)00052-6. 
[11] A.M. Brown, M.F. Ashby, Correlations for Diffusion Constants., Acta Metall. 28 (1980) 10851101. doi:10.1016/0001-6160(80)90092-9.

[12] P.G. Charalambides, H.C. Cao, J. Lund, A.G. Evans, Development of a test method for measuring the mixed mode fracture resistance of bimaterial interfaces, Mech. Mater. 8 (1990) 269-283. doi:10.1016/0167-6636(90)90047-J.

[13] K. Matoy, T. Detzel, M. Müller, C. Motz, G. Dehm, Interface fracture properties of thin films studied by using the micro-cantilever deflection technique, Surf. Coatings Technol. 204 (2009) 878-881. doi:10.1016/j.surfcoat.2009.09.013.

[14] T.P. Weihs, S. Hong, J.C. Bravman, W.D. Nix, Mechanical deflection of cantilever microbeams: A new technique for testing the mechanical properties of thin films, J. Mater. Res. 3 (1988) 931-942. doi:10.1557/JMR.1988.0931.

[15] M.J. Cordill, D.F. Bahr, N.R. Moody, W.W. Gerberich, Recent Developments in Thin Film Adhesion Measurement, IEEE Trans. Device Mater. Reliab. 4 (2004) 163-168. doi:10.1016/j.msea.2006.08.027.

[16] M.D. Kriese, W.W. Gerberich, N.R. Moody, Quantitative adhesion measures of multilayer films: Part I. Indentation mechanics, J. Mater. Res. 14 (1999) 3007-3018. doi:10.1557/JMR.1999.0404.

[17] M.D. Kriese, W.W. Gerberich, N.R. Moody, Quantitative adhesion measures of multilayer films: Part II. Indentation of W/Cu, W/W, Cr/W, J. Mater. Res. 14 (1999) 3019-3026.

doi:10.1557/JMR.1999.0405.

[18] D.B. Marshall, A.G. Evans, Measurement of adherence of residually stressed thin films by indentation. I. Mechanics of interface delamination, J. Appl. Phys. 56 (1984) 2632-2638. doi:10.1063/1.333794.

[19] S.J. Bull, Failure mode maps in the thin film scratch adhesion test, Tribol. Int. 30 (1997) 491-498. doi:10.1016/S0301-679X(97)00012-1.

[20] S.J. Bull, E. G.-Berasetegui E., Chapter 7 An overview of the potential of quantitative coating adhesion measurement by scratch testing, in: Tribol. Interface Eng. Ser., 2006: pp. 99-114. doi:10.1016/S0167-8922(06)80043-X.

[21] S.J. Bull, Failure modes in scratch adhesion testing, Surf. Coatings Technol. 50 (1991) 25-32. doi:10.1016/0257-8972(91)90188-3.

[22] A. Kleinbichler, J. Zechner, M.J. Cordill, Buckle Induced Delamination Techniques to Measure the Adhesion of Metal Dielectric Interfaces, Microelectron. Eng. (2016). doi:10.1016/j.surfcoat.2016.08.074.

[23] A. Roshanghias, G. Khatibi, R. Pelzer, J. Steinbrenner, On the effects of thickness on adhesion of TiW diffusion barrier coatings in silicon integrated circuits, Surf. Coatings Technol. 259 (2014) 386-392. doi:10.1016/j.surfcoat.2014.10.065.

[24] A. Roshanghias, R. Pelzer, G. Khatibi, J. Steinbrenner, Thickness dependency of adhesion properties of TiW thin films, in: Proc. 16th Electron. Packag. Technol. Conf. EPTC 2014, 2014: pp. 192-195. doi:10.1109/EPTC.2014.7028417.

[25] P.A. Steinmann, Y. Tardy, H.E. Hintermann, Adhesion testing by the scratch test method: The influence of intrinsic and extrinsic parameters on the critical load, Thin Solid Films. 154 (1987) 333-349. doi:10.1016/0040-6090(87)90377-4. 
[26] D.F. Bahr, J.W. Hoehn, N.R. Moody, W.W. Gerberich, Adhesion and acoustic emission analysis of failures in nitride films with a metal interlayer, Acta Mater. 45 (1997) 5163-5175.

doi:10.1016/S1359-6454(97)00180-8.

[27] J.W. Hutchinson, Z. Suo, Mixed Mode Cracking in Layered Materials, Adv. Appl. Mech. 29 (1991) 63-191. doi:10.1016/S0065-2156(08)70164-9.

[28] D.M. Többens, S. Zander, KMC-2: an X-ray beamline with dedicated diffraction and XAS endstations at BESSY II, J. Large-Scale Res. Facil. JLSRF. 2 (2016) 1-6. doi:10.17815/jlsrf-2-65.

[29] I.C. Noyan, J.B. Cohen, Residual stress: measurement by diffraction and interpretation, SpringerVerlag, Berlin, 1987.

[30] A.G. Dirks, R.A.M. Wolters, A.J.M. Nellissen, On the microstructure-property relationship of WTi(N) diffusion barriers, Thin Solid Films. 193-194 (1990) 201-210. doi:10.1016/S00406090(05)80028-8.

[31] I.J. Raaijmakers, T. Setalvad, A.S. Bhansali, B.J. Burrow, L. Gutai, K.B. Kim, Microstructure and barrier properties of reactively sputtered Ti-W nitride, J. Electron. Mater. 19 (1990) 1221-1230. doi:10.1007/BF02673336.

[32] E. Eiper, K.J. Martinschitz, I. Zizak, N. Darowski, J. Keckes, X-ray elastic constants determined by the combination of $\sin 2 \psi$ and substrate-curvature methods, Zeitschrift Für Met. 96 (2005) 1069-1073.

[33] G.G. Stoney, The Tension of Metallic Films Deposited by Electrolysis, Proc. R. Soc. A Math. Phys. Eng. Sci. 82 (1909) 172-175. doi:10.1098/rspa.1909.0021.

[34] D. Nečas, P. Klapetek, Gwyddion: an open-source software for SPM data analysis, Open Phys. 10 (2012) 181-188. doi:10.2478/s11534-011-0096-2.

[35] P.A. Flinn, Principles and applications of wafer curvature techniques for stress measurements in thin films, Mat Res Soc Symp Proc. 130 (1989) 41-51. doi:10.1557/PROC-130-41. 